\title{
GAMIFICAÇÃO NAS AULAS DE GEOGRAFIA "LENDO IMAGENS E ATUALIDADES": UMA EXPERIÊNCIA EM ENSINO MÉDIO PÚBLICO
}

\author{
LORENA/SP MAIO/2018
}

\author{
Marco Antonio de Oliveira - SEESP - marcooliveira@prof.educacao.sp.gov.br \\ Neide Aparecida Arruda de Oliveira - UNIFATEA - mnoliveira9@gmail.com \\ Maria Cristina Marcelino Bento - UNIFATEA - criscabento@gmail.com \\ Luciani Vieira Gomes Alvareli ～- UNIFATEA - Iuciani.alvareli@gmail.com
}

Tipo: Relato de Experiência Inovadora (EI)

Categoria: Métodos e Tecnologias

Setor Educacional: EDUCAÇÃO MÉDIA E TECNOLÓGICA

\begin{abstract}
RESUMO
Tendo em vista a falta de motivação dos alunos para interagir com as aulas, os recursos oferecidos pela gamificação mostraram-se bastante pertinentes ao contexto desta pesquisa. Na esfera da escola pública, muito se tem discutido acerca dos motivos que levam os alunos a não participarem das aulas, desde desinteresse e distanciamento dos assuntos e práticas, a questões sociais ligadas à idade, grupos de amizade e acompanhamento familiar. Desse modo, este estudo tem como objetivo relatar uma experiência de gamificação com alunos do $1^{\circ}$ ano do Ensino Médio de uma escola pública do interior de São Paulo em aulas de geografia por meio da proposta "Lendo imagens e atualidades". Os resultados apontaram que a aplicação da gamificação nas aulas fez com que os alunos interagissem mais com as aulas e com o professor e também apresentaram subsídio para uma discussão acerca de imagens geográficas, discurso, identidade e cidadania.
\end{abstract}

Palavras-chave: gamificação, Geografia, Ensino Médio público, letramento crítico. 


\section{INTRODUÇÃO}

O cenário global digital convive com o rápido avanço das tecnologias e mídias digitais de modo que os padrões de relacionamento humano e a comunicação ganham novas configurações e demandas. Nessa perspectiva, a forma de se gerir informação e construir conhecimento também recebe novos olhares e reflexões. Nesse contexto, surge uma abordagem de gamificação em que se busca a utilização de elementos de design de jogos que não acontecem obrigatoriamente em espaços de jogos. O que se entende, então, é uma proposta que pressupõe de uma aplicabilidade com vista ao engajamento entre pessoas, com respaldo em produções socialmente significativas e propostas a soluções de problemas.

A partir desse entendimento, este trabalho busca tecer uma interface entre a gamificação e as aulas de geografia, a partir da qual se traça uma correspondência com o uso da linguagem como forma de cidadania e diálogo para mudanças, tendo como base as premissas do letramento crítico. Essa proposta se justifica a partir das necessidades de discussão entre os padrões local e global da geografia e suas implicações no contexto dos alunos e, também, baseia-se em nosso entendimento de formação de cidadãos críticos e preparados para o diálogo construtivo.

Assim, as atividades foram desenvolvidas com grupos de alunos do $1^{\circ}$ ano do Ensino Médio público em uma escola do interior do estado de São Paulo. A metodologia deste trabalho descreve as etapas e tópicos abordados e os resultados refletem acerca da capacidade dos alunos de reconhecer e discutir pontos de cultura local e global. Como respaldo teórico, buscamos referências em gamificação em autores como Watkins (2006), Kapp (2012) e Formanski e Alves (2015), e em letramentos e cidadania em Soares (1998), Mattos (2015) e Rojo (2016). A partir disso, discute-se o papel desses elementos para a formação crítica e para a cidadania em uma perspectiva mais ampla que direitos e deveres, mas também a discussão acerca de ações para mudanças.

\section{GAMIFICAÇÃO E PRÁTICAS EDUCACIONAIS}

Uma mudança de pensamento acerca de para quê se deve ensinar o que se ensina na escola tem aberto espaço para discussões acerca de práticas situadas e também formas de aprendizagem fora da sala de aula. Isso vai ao encontro do que afirma Watkins (2006), ao passo que o autor aponta para uma valorização das experiências de vida e de aprendizagem fora da sala de aula como itens indispensáveis para a formação de um 
grupo que reconstrói conceitos a todo o tempo em que se encontra em ambiente escolar. Entretanto, a realidade da educação brasileira é que na maioria dos casos são valorizadas apenas as formas de letramento da letra em detrimento das outras possibilidades, como o letramento digital.

Quanto ao letramento digital e às mídias sociais aplicadas à educação, temos visto significativo aumento em propostas, grupos de estudos e pesquisas relevantes a nível nacional e internacional, o que valida vertiginosamente as propostas de gamificação. $O$ termo, de acordo com Formanski e Alves, refere-se ao uso dos atributos de jogo para dirigir o comportamento do jogador em um contexto não jogo. Ou seja, utiliza técnicas de jogos em diferentes situações para aumentar a motivação das pessoas envolvidas em determinada atividade que elas normalmente consideram entediantes. Permite encorajar determinados comportamentos, tirando vantagem da predisposição psicológica do ser humano em se engajar nos jogos.

Concordando com os autores acima citados, temos uma perspectiva que leva em conta os aspectos emocionais nas aulas uma vez que representam benefícios como motivação externa, aspectos sociais que propiciam interação e também aspectos estratégicos, fazendo uso de diferentes técnicas aplicadas a diferentes contextos.

\section{LETRAMENTOS E CIDADANIA}

As discussões sobre letramentos têm ganhado força, e nosso ponto de partida para a discussão é primeiramente postular o conceito como uma prática social. Com respaldo em Soares (1998), enfatizamos que as práticas letradas não são, de modo algum, propensas à neutralidade, pelo contrário, são carregadas de sentido e formas de leitura do mundo. Ainda mais, as práticas letradas não se referem apenas ao uso da escrita, mas estão intimamente ligadas à capacidade de comunidades formarem identidade.

Seguindo o pensamento, concordamos com Soares ao definir letramento como algo que "as pessoas fazem com as habilidades de leitura e de escrita, em um contexto específico" (p. 72), o que nos abre espaço para as seguintes indicações: a) letramento é prática, o modo de se fazer uso da linguagem; b) essa prática é significativa e situada em contexto; c) ao passo que se refere ao modo como as pessoas fazem uso das habilidades de leitura e escrita, letramento se liga à cultura e identidade de 
comunidades. Usamos letramentos pela gama de práticas atualmente desenvolvidas e a complexidade das diferentes práticas letradas.

Ao se tomar letramento como prática social, concebemos que tanto o conhecimento quanto a realidade estão sendo formados em um processo contínuo, ou seja, podemos dizer que esses [...] se constituem em processos dialéticos e contínuos de construção e reconstrução de visões do mundo, ou realidades diárias, que os indivíduos e os grupos sociais realizam em interação com a sociedade (Mattos, 2003).

Mattos (2003) aponta para a formação de conhecimento a partir de interações com a sociedade, o que claramente nos coloca a necessidade de a escola estar conectada às reais necessidades dos alunos. Nessa discussão, emerge a noção de cidadania, essencial para discutirmos questões como identidade, linguagem e práticas de gamificação. Sobre isso, Mattos enfatiza a visão de cidadania como a manifestação de uma consciência de responsabilidade coletiva e, nesse ponto, não nos posicionamos apenas sobre direitos e deveres na esfera civil, mas também sobre a consciência da cultura e da formação identitária das comunidades em estreita influencia com os fenômenos globais. Mattos (2003) ainda atrela esse conceito ao de eventos públicos e/ou celebrações e, com respaldo em Monte Mór, aponta para cidadania como um fenômeno com o qual "as pessoas se identificam mais de perto".

Como dito anteriormente, essas práticas letradas se fundamentam em relações sociais e, repensando a contemporaneidade, Mattos também reflete acerca da confluência de culturas e atividades que decorre a internet. A partir da internet formam-se as "novas comunidades globais dentro das quais o cidadão pode agir dentro de uma nova esfera pública" (MATTOS, 2003). O que destacamos nesse apontamento é o fato de novos deveres, responsabilidades e modos de atuação passarem a existir haja vista o surgimento de novas comunidades que não mais se limitem por fronteiras espaçotempo.

Em outra instância, concordamos com Mattos ao conceber as práticas críticas e reflexivas como forma de empoderamento. Nas palavras da autora, "o letramento crítico, aliado à educação para a cidadania, promove a conscientização dos educandos, empoderando-os e preparando-os para tornarem-se cidadãos críticos e pró-ativos" (MATTOS, 2003).

Recapitulando, nossa visão de prática e gamificação tem respaldo na discussão de reconhecimento de valores, cidadania e práticas críticas que buscam refletir acerca do espaço físico em patamares local e global e suas relações, de modo que as imagens 
estudadas nas aulas de geografia estão carregadas de sentido e se formam em um discurso dialógico a partir das experiências e conhecimento de mundo dos alunos estudados pela pesquisa.

\section{METODOLOGIA}

Com a finalidade de se fazer uma avaliação diagnóstica para saber como os alunos do $1^{\circ}$ ano do Ensino Médio estão chegando após concluírem o ensino Fundamental II, foi realizada a atividade de gamificação que foi aplicada no $1^{\circ}$ semestre de 2016, na primeira semana de aula, no mês de fevereiro. Esta experiência utilizou duas aulas de 50 minutos na disciplina de Geografia em uma escola pública situada no interior do estado de São Paulo. Vinte e cinco alunos participaram do quiz de Geografia do Brasil. Essa disciplina consta na grade curricular do Ensino Médio e são duas aulas semanais subsequentes.Na primeira aula, os alunos foram divididos em cinco grupos de cinco estudantes. $O$ grupo que acertasse mais questões, em um total de 17, ganharia uma caixa de bombom como prêmio. Inicialmente, o recurso utilizado foi o projetor para mostrar as questões baseadas em imagens sobre geografia física e geografia do Brasil quando são trabalhados os conceitos de espaço e paisagem. No primeiro slide constam as orientações para a realização do jogo, como segue:

\section{"QUIZ" \\ A seguir você verá uma série de imagens. \\ Após vê-las responda, o que se pede, marcando a alternativa escolhida no seu gabarito.}

Figura 1: Abertura do quiz

Em seguida, são entregues as planilhas que são os gabaritos a cada grupo. Nesse gabarito, constam nomes dos alunos, a data da realização do quiz e a série, assim como a numeração das dezessete questões dadas com quatro alternativas (A, B, C, D). Há também a possibilidade de se fazer essa atividade de gamificação de forma individualizada. A partir do slide quatro, inicia-se o quiz com a questão "Essa imagem representa", disponibilizando aos alunos um minuto para que olhem, analisem e 
discutam sobre a imagem e marquem na planilha, como no exemplo abaixo.

\section{1- Essa imagem representa:}

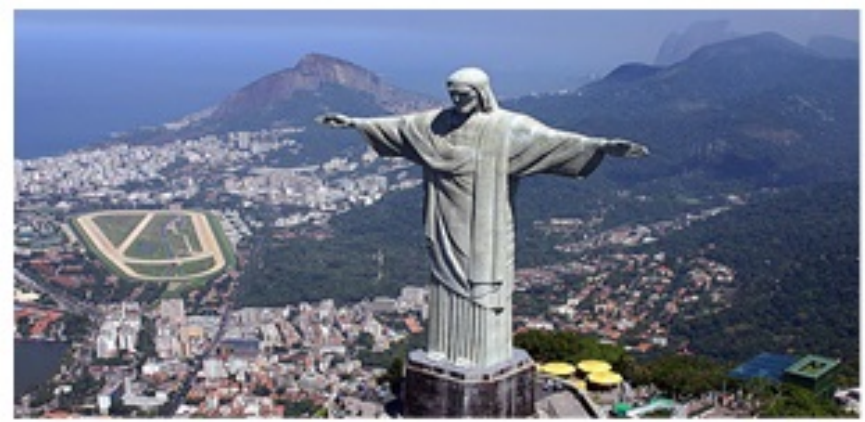

Figura 2: Cristo Redentor

Em seguida aparecem as alternativas como exemplificado abaixo:

a) A estátua da Liberdade que fica na Cidade de Nova lorque;

b) A estátua do Cristo Redentor que fica na Cidade do Rio de Janeiro:

c) A estátua do Cristo Redentor, que fica na Cidade nordestina de mesmo nome;

d) A estátua do Padre Cícero, que em Juazeiro do Norte.

Figura 3: alternativas

As questões seguiram o modelo apresentado acima, com as seguintes abordagens:

\begin{tabular}{|l|}
\hline Tópicos utilizados nas aulas \\
\hline Identificar o espaço em que se vive \\
\hline Identificar uma bússola e seu uso \\
\hline Identificar os cinco continentes \\
\hline Identificar a bandeira do Estado de São Paulo \\
\hline Reconhecer monumentos culturalmente famosos, como a Estátua da Liberdade \\
\hline Reconhecer o conceito de globalização a partir de marcas estampadas em um Papai Noel \\
\hline Identificar a princesa Isabel \\
\hline Identificar o menor e o maior estados da região sudeste \\
\hline Verificar se alunos reconhecem bandeiras de outros estados brasileiros \\
\hline
\end{tabular}


Reconhecer uma pirâmide do Egito

Verificar os estados da região sudeste com litoral

Reconhecer um homem pré-histórico

Pontuar as capitais do Brasil

Identificar o rio Paraíba do Sul, importante na região

Identificar a cidade mais populosa do país

\section{Tabela 1: tópicos do quiz}

Um ponto que destacamos é a variação das imagens em relação às realidades local e global esperando resultados a partir de suas relações de poder e influência, ou seja, esperávamos que os alunos conhecessem mais em escala global.

Um exemplo é o seguinte: a figura 4 (questão 15) abaixo exibe o rio Paraíba do Sul, importante na região, e a figura 5 (questão 6) exibe a Estátua da Liberdade.

\section{5- Essa imagem representa:}

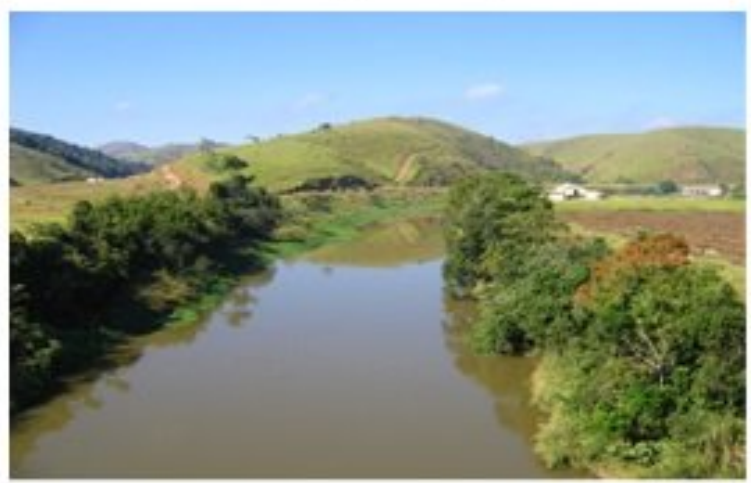

Figura 4: Rio Paraíba do Sul

6- Essa imagem representa:

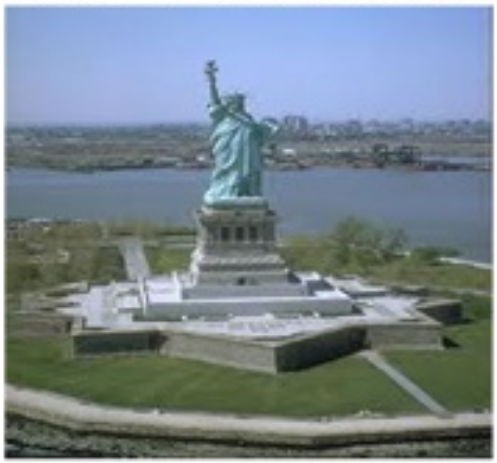


Figura 5: Estátua da Liberdade

O último slide da atividade apresentou uma tirinha, reproduzida logo abaixo. O objetivo aqui foi o de verificar se alunos reconheciam a referências aos movimentos de rotação e translação.

\section{7- Nessa tirinha a personagem Mafalda está falando de um dos movimento da terra: O movimento do planeta terra ilustrado na charge da Mafalda é:}
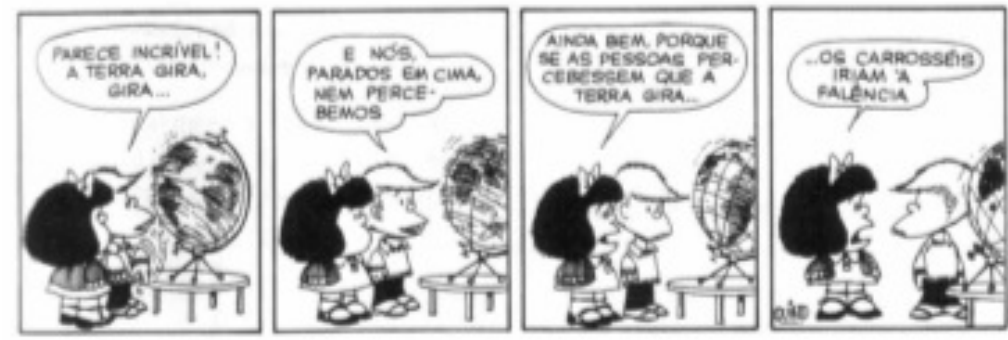

Figura 6: Tirinha da Mafalda

\section{RESULTADOS, ANÁLISES E CONCLUSÃO}

Quanto aos dados de ordem quantitativa, temos que dos cinco grupos, o melhor resultado foi de 10 questões certas de um total de 17 questões apresentadas, ou seja, $58 \%$. O segundo grupo com melhor resultado acertou 9 questões, ou seja, 52\%. Já o terceiro e o quarto grupos acertaram 6 questões, 35\% respectivamente. E o último grupo acertou 5 questões correspondendo a 29\%. Em análise geral, o resultado mostrou-se abaixo o esperado, apontando para deficiência no reconhecimento de itens básicos para a geografia local e global. Falando de dados qualitativos e propostas, podemos apontar para alguns pontos que podem se conectar às futuras práticas das aulas de geografia com vista à linguagem e cidadania: a discussão social e significativa do espaço local, com investigação e mapeamento de aspectos físicos e culturais; novas práticas de gamificação objetivando produções que apresentem cultura local e global; uso de mídias digitais para se discutir diferentes realidades e contextos e socialização dos dados. 
FORMANSKI, F. N.; ALVES, J. B. Gamificação aplicada à aprendizagem de grupo. XI Congresso Nacional de Excelência em Gestão, Agosto de 2015. Disponível em: http://www.inovarse.org/sites/default/files/T_15_429.pdf

KAPP, Karl. The Gamification of Learning and Instruction: Game-based Methods and Strategies for Training and Education. Pfeiffer, 2012.

MATTOS, A. M. A. Ensino de Inglês como língua estrangeira na escola pública: letramentos, globalização e cidadania. Jundiaí: Paco Editorial, 2015.

ROJO, R. Pedagogia dos Multiletramentos. Programa Escrevendo o Futuro. 2016. Disponível em: https://www.youtube.com/watch?v=IRFrh3z5T5w. Acesso em 02 de agosto de 2017.

SOARES, M. Letramento: um tema em três gêneros. $2^{\underline{a}}$ ed. Belo Horizonte: Autêntica, 1998.

WATKINS, R. Preparing E-Learners for Online Success. Learning Circuits, Article, 2006. 